\title{
O TRIBUNAL PENAL INTERNACIONAL, A VIOLAÇÃO EM MASSA DOS DIREITOS HUMANOS E A CONDENAÇÃO PARADIGMÁTICA NO CASO THOMAS LUBANGA
}

\author{
Andreia Alves de Almeida ${ }^{156}$ \\ Oscar Francisco Alves Junior ${ }^{157}$
}

Recebido em: 25/10/2016

Aprovado em: 15/02/2017

\begin{abstract}
RESUMO
O presente artigo aborda a criação do Tribunal Penal Internacional (TPI), sua importância no cenário internacional, a partir de sua posição adotada frente a violação em massa dos Direitos Humanos, em que determinou a prisão e após o devido processo legal a condenação de Thomas Lubanga Dyilo, ex-chefe rebelde do nordeste congolês por ter recrutado crianças e adolescentes transformando os meninos em soldado e as meninas escravas sexuais durante a guerra no leste da República Democrática do Congo. A pesquisa histórico-bibliográfica exposta de forma argumentativa identifica o TPI como um dos instrumentos para uma governança global no terceiro milênio, no que se refere ao processo e julgamento na esfera penal.
\end{abstract}

Palavras-Chave: Direitos humanos. Tribunal penal internacional. Crianças. Condenação.

\section{INTRODUÇÃO}

A paz, a segurança e o bem-estar da humanidade têm sido atingidos em razão da prática de graves crimes, gerando sensação de impunidade à comunidade internacional pela falta de apuração e sanção aos infratores.

Nem sempre a jurisdição nacional tem sido suficiente para estabelecer a prevenção e repressão quanto à prática de violações aos direitos humanos, principalmente quando

\footnotetext{
156 Doutoranda em Ciências Jurídicas DINTER entre a UNIVALI/SC e FCR/RO. Mestra em Direito pela UNIVEM/SP. Especialista em Segurança Pública e Direitos Humanos pela UNIR/RO. Professora dos Cursos de Direito e Gestão Ambiental da UNIRON/RO e do Curso de Direito da Faculdade Católica de Rondônia.

${ }^{157}$ Doutorado em andamento em Ciência Jurídica pela Universidade do Vale do Itajaí - UNIVALI. Mestre em Educação pela Universidade Federal de Mato Grosso do Sul - UFMS. Mestrado profissional em Poder Judiciário pela Fundação Getúlio Vargas - FGV. Bacharel em Direito pela Instituição Toledo de Ensino - ITE. Professor na Escola da Magistratura de Rondônia. Juiz de Direito do Tribunal de Justiça de Rondônia.
} 
perpetradas em massa por pessoas que exercem altos cargos no cenário nacional respectivo. Assim, surge a ideia de um órgão internacional com atuação complementar à jurisdição penal nacional.

Sob este prisma, este texto se justifica, haja vista que a violação dos direitos humanos é assunto relevante ensejando enfrentamento teórico e prático, despertando a atenção nacional e internacional. Todavia, consciente de que conforme debate Bobbio"158 "teoria e prática percorrem duas estradas diversas e a velocidades muito desiguais".

Por isso, a violação dos direitos humanos, a criação de um órgão apto para julgar esses atos e a efetividade das decisões são questões que conduzem a necessidade de enfrentamento, pois as eventuais condenações servem de paradigma internacional e contribuem na prevenção de futuros atos criminosos, como é o Caso do Julgamento do congolês Thomas Lubanga Dyilo.

Diante disso, o objetivo deste artigo é abordar a criação do Tribunal Penal Internacional (TPI), sua importância no cenário internacional, a partir de sua posição adotada frente a violação em massa dos Direitos Humanos, em que determinou a prisão, processamento e posterior condenação de Thomas Lubanga, ex-chefe rebelde do nordeste congolês por ter recrutado crianças e adolescentes transformando os meninos em soldado e as meninas escravas sexuais durante a guerra no leste da República Democrática do Congo.

Como estratégia metodológica o texto foi dividido em cinco partes, primeiramente identificando os direitos humanos e sua construção histórica e na sequência a criação do Tribunal Penal Internacional (TPI), bem como a jurisdição e competência desta Corte. Por fim, nas duas últimas partes aborda-se o julgamento propriamente dito do congolês Thomas Lubanga Dyilo e a seqüência cronológica do procedimento adotado segundo o Estatuto de Roma.

Para esse fim utilizou-se as técnicas do referente, da categoria e dos conceitos operacionais, conforme Passold ${ }^{159}$.

A pesquisa histórico-bibliográfica mediante a técnica do fichamento é exposta de forma argumentativa identificando o TPI como um dos instrumentos para uma governança global no terceiro milênio, no que se refere ao processo e julgamento na esfera penal.

Enfim, por si só, a violação dos direitos humanos é prática que assombra a comunidade mundial, independente de ideologia ou cultura, entretanto em escala exponencial abala ainda mais quando praticada contra crianças e adolescentes, vez a proteção destes se realiza pela

\footnotetext{
${ }^{158}$ BOBBIO, Norberto. A era dos Direitos. $15^{a}$ tiragem. Rio de Janeiro: Campus, 1992. p.67

159 PASSOLD, Cesar Luiz. Metodologia da Pesquisa Jurídica: teoria e prática. $12^{\mathrm{a}}$ ed. São Paulo: Conceito Editorial, 2011.
} 
"cooperação de toda a comunidade de forma articulada, pois desta maneira se beneficiarão não só as crianças e os adolescentes, mas também toda a sociedade", conforme argumenta Oscar Alves Junior ${ }^{160}$.

Os atos de Lubanga violando direitos humanos no Congo repercutiram internacionalmente, vitimando crianças e adolescentes e atingindo de forma direta e indireta as gerações presentes e as futuras.

\section{DIREITOS HUMANOS E SUA CONSTRUÇÃO HISTÓRICA}

A humanidade empreendeu uma longa jornada até o reconhecimento e estabelecimento do conteúdo do conceito de dignidade da pessoa humana, até consubstanciar-se em princípio fundamental aplicável a todo ser humano desde sua concepção no útero materno.

Nesse sentido da universalidade da dignidade da pessoa humana Comparato explica que:

todos os seres humanos, apesar das inúmeras diferenças biológicas e culturais que os distinguem entre si, merecem igual respeito, como únicos entes no mundo capazes de amar, descobrir a verdade e criar a beleza". Em razão desse reconhecimento universal, conclui: "ninguém - nenhum indivíduo, gênero, etnia, classe social, grupo religioso ou nação - pode afirmar-se superior aos demais ${ }^{161}$.

Destaca-se que a noção de direitos humanos foi cunhada ao longo dos últimos três milênios da civilização, sendo, porém, um conceito do mundo moderno. Aliás, o 'conteúdo' deste conceito é questão intrigante, ao lado das perguntas 'por quê' e 'para quê' existem os direitos humanos, conforme argumenta Leite ${ }^{162}$. Argumenta o referido autor que Direitos Fundamentais ou Direitos Humanos evoluem através dos tempos, por isso é necessário estudar seu processo de formação, pois ele se amolda de acordo com cada época ou período distinto da humanidade e, assim, necessária sua positivação para a proteção da dignidade da pessoa humana.

\footnotetext{
160 ALVES JUNIOR, Oscar Francisco. Estatuto da Criança e do Adolescente: O Conselho Tutelar e sua Prática Educativa. Revista Emeron no 23, 2012. p.63.

${ }^{161}$ COMPARATO, Fábio Konder. A Afirmação Histórica dos Direitos Humanos. 7. a ed. São Paulo: Saraiva, 2010. p.1.

${ }^{162}$ GARCIA, Marcos Leite. Direitos Humanos como conceito histórico da humanidade. IV Encontro Anual da Andhep. Vitória, $2008 . \quad$ p.8, $\quad$ disponível <http://www.andhep.org.br/anais/arquivos/IVencontro/MarcosLeiteGarcia.pdf>. Acesso em 15 de jul. 2015.
} 
Na obra História e Evolução dos Direitos Humanos ${ }^{163}$ de Peces-Barba, os Direitos Fundamentais são apresentados com um conceito histórico, onde o autor espanhol traça uma linha de evolução dos direitos fundamentais ou direitos humanos a partir do que denomina de "trânsito a modernidade" por um conceito do mundo moderno que surge de uma progressão desde o período medieval. Segundo seu ensino, o período se inicia no século XIV e vai até o século XVIII, no qual a sociedade vai se amoldando e se preparando para o surgimento dos direitos fundamentais, sendo que faz comparação do período medieval com o período do renascimento da Europa, o qual é marcado por profundas alterações políticas, religiosas, intelectuais e sociais, sendo substituída progressivamente para uma sociedade capitalista. Contudo essa transição do feudalismo ao capitalismo foi lenta, até chegar ao mercantilismo.

Neste mesmo texto Peces Barba cita quatro traços decisivos para a construção dos direitos fundamentais: a secularização, o naturalismo, o racionalismo e o individualismo. Assim, as mudanças na sociedade principalmente no Ocidente, moldariam o conceito de direitos fundamentais; graças a contribuição do iusnaturalismo racionalista que será a coexistência desse novo Direito. E finalmente identifica em outra fase os Direitos Fundamentais como uma dimensão internacional, cuja origem remonta a luta da escravatura (1815-1880) destacando o Tratado de Londres 1841 e posteriormente outros tratados internacionais para proibição do comércio de escravos e conferências internacionais como a Conferência de Berlim. Depois da II Guerra Mundial menciona a Declaração de 1948, em seu artigo 14, para abolição do comércio de escravos e da escravatura.

Muitos são os acontecimentos que culminaram para a construção histórica dos Direitos Humanos, mas sem dúvida com a Revolução Francesa emergiram ideais representativos dos direitos humanos, a liberdade, a igualdade e a fraternidade. Sendo fonte de inspiração aos teóricos e transformaram todo o modo de pensar ocidental, onde os homens tinham plena liberdade, eram iguais, ao menos em relação à lei, e deveriam ser fraternos, auxiliando uns aos outros.

Assim com a barbárie ocorrida na Segunda Grande Guerra, os homens se conscientizaram da necessidade de evitar que tamanha monstruosidade não ocorresse novamente, cabendo aos Estados prevenir e coibir através da criação de um organismo internacional. As circunstâncias culminaram na criação da Organização das Nações Unidas

\footnotetext{
${ }^{163}$ PECES-BARBA, Gregorio. La diacronía del fundamento y del concepto de los Derechos: el tiempo de la historia. Curso de Derechos Fundamentales: teoría general. Madrid: Universidad Carlos III de Madrid, 1995, cap V.
} 
(ONU) e na declaração de inúmeros Tratados Internacionais de Direitos Humanos, como "A Declaração Universal dos Direitos do Homem”, como ideal comum de todos os povos. Assim demais documentos e organismos surgiram progressivamente. Confirmando esse pensamento Piovesan ${ }^{164}$ :

O Tribunal de Nuremberg, em 1945-1946, significou um poderoso impulso ao movimento de internacionalização dos direitos humanos. Ao final da Segunda Guerra e após intensos debates sobre o modo pelo qual poder-se-ia responsabilizar os alemães pela guerra e pelos bárbaros excessos do período, os aliados chegaram a um consenso, com o Acordo de Londres de 1945, pelo qual ficava convocado um Tribunal Militar Internacional para julgar os criminosos de guerra.

Após criação da ONU surgem outros organismos internacionais, dentre eles ocorre a criação do Tribunal Penal Internacional (TPI), a partir de grandes discussões e lutas travadas sobretudo pela Comissão de Direitos Humanos da Câmara dos Deputados na seara internacional, os quais defendiam a aplicação do Princípio da Justiça Universal pela criação de um tribunal permanente, para conter as injustiças cometidas no âmbito de jurisdições internas dos países.

No caso Lubanga, em análise neste trabalho, o TPI será o órgão competente para julgar o líder congolês e com grande repercussão no cenário internacional.

\section{A CRIAÇÃO DO TRIBUNAL PENAL INTERNACIONAL (TPI)}

Após o final da II Guerra Mundial, as Nações Unidas cogitaram a ideia de estabelecer o Tribunal Penal Internacional (TPI), assim entre os anos 1993 e 1994 instituíram dois tribunais especiais para punir as graves violações do direito internacional humanitário ocorridas na exIugoslávia e em Ruanda, respectivamente.

O Tribunal Penal Internacional (TPI) pode-se dizer foi a consagração máxima da garantia aos Direitos Humanos, conquistados lentamente pela sociedade após guerras sangrentas e graves violações aos direitos humanos.

O TPI foi criado na Conferência Diplomática de Plenipotenciários das Nações Unidas sobre o Estabelecimento de um Tribunal Penal Internacional, a qual foi realizada na Cidade de

\footnotetext{
${ }^{164}$ PIOVESAN, Flávia. Direitos Humanos e o Direito Constitucional Internacional. 3. a ed. Max Lemonad,
} 1997. p.120-1. 
Roma, entre os dias 15 de junho a 17 de julho de 1998. Conforme Lewandowski ${ }^{165}$ a criação do TPI foi aprovada por maioria, sendo 120 votos a favor, 7 contra (EUA, China, Filipinas, Índia, Israel, Sri Lanka e Turquia) e 21 abstenções.

Em que pese a resistência de algumas nações a tendência é gradual e constante e como argumenta Fritjof Capra ${ }^{166}$ trata-se de uma nova visão da realidade que é explorada no âmbito de novas instituições.

Destaca-se que essa criação através do Estatuto do Tribunal possui a natureza jurídica de tratado e com data para entrada em vigor após sessenta Estados manifestarem o consentimento em vincularem-se ao TPI, de acordo com suas normas de competência interna para a celebração de tratados.

O TPI é composto pelos seguintes órgãos:

a) A Presidência;

b) Uma Seção de Recursos, uma Seção de Primeira Instância e uma Seção de Questões Preliminares;

c) o Gabinete do Promotor;

d) a Secretaria.

No ano de 1994 inicia-se uma série de negociações para estabelecer o tribunal que tivesse competência sobre os crimes mais graves para a comunidade internacional, independente do lugar em que foram cometidos, aplicando-se o Princípio da Justiça Universal.

Entende-se por esse princípio que acarreta a não aplicabilidade das limitações legais em relação a crimes que afetam a toda humanidade, ou seja, superando a aplicabilidade do Princípio da Territorialidade de cada país, como exemplo no Brasil o artigo $7^{\circ}$ do Código Penal e, assim, aplica-se o Princípio da Jurisdição Universal, de forma que nenhum crime que viole os Direitos Humanos permaneça impune e seja alegado questões de soberania.

A sociedade moderna globalizada desenvolve-se rumo a construção de uma governança global no terceiro milênio pós Jesus Cristo, conforme calendário adotado pela maioria das nações mundiais, sendo que a criação do TPI é órgão que contribui nesse prisma, em que pese

\footnotetext{
${ }^{165}$ LEWANDOWSKI, Enrique Ricardo. O Tribunal Penal Internacional: de uma cultura de impunidade para uma cultura de responsabilidade, disponível em <http://www.scielo.br/scielo.php?script=sci_arttext\&pid=S0103-40142002000200012\#not1>. Acesso em: 20 de ago. 2015.

${ }^{166}$ CAPRA, Fritjof. O ponto de mutação. $30^{\mathrm{a}}$ reimpressão. São Paulo: Cultrix, 2014. p.259.
} 
exercer sua jurisdição sobre pessoas e não sobre nações. Corroborando esse entendimento Biato $^{167}$ argumenta:

\begin{abstract}
O fortalecimento do TPI representa muito mais do que uma vitória no combate a crimes que ferem nossa consciência humanista. Representa passo decisivo na luta contra a impunidade e na construção da paz sustentável e duradoura. Vivemos num mundo cada vez mais interdependente, onde se multiplicam ameaças e desafios interconectados. Para problemas globalizados demandam-se respostas e soluções igualmente universais. Não pode haver, em nenhuma esfera, exceções quando se trata de instituir mecanismos de controle e fiscalização. O risco é a perda de credibilidade e eficácia na construção de uma governança global para o século 21.
\end{abstract}

Dentre outros princípios, o TPI observa o princípio da complementariedade e somente exerce sua jurisdição internacional quando o Estado que tem a jurisdição nacional não inicia o processo com relação ao infrator, ou mesmo o fazendo procura excluí-lo de eventual punição ou então minora a sanção. Entretanto, o bis in idem não é autorizado, conforme artigo 20 do Estatuto.

O princípio da universalidade também é aplicável no TPI, vez que o Estados-partes se sujeitam de forma que todos os casos previstos, e não apenas alguns a seu critério, serão apreciados na esfera internacional.

Apesar deste princípio, permite-se que os Estados possuidores de legislação penal que reconheça o princípio da extraterritorialidade, processe e julgue um infrator que tenha praticado crimes que seriam da competência do TPI.

\title{
3.1 Tribunal Penal Internacional: Jurisdição e Competência
}

A Jurisdição e a Competência do Tribunal Penal Internacional (TPI) são dois institutos importantes de serem registrados neste trabalho que aponta a atuação desta Corte no Caso Thomas Lubanga.

A Jurisdição é o poder de dizer o direito, que é efetivado por um terceiro imparcial em uma situação concreta buscando a realização do Direito, sendo que no caso do TPI a jurisdição será exercida se um Estado-parte comunicar ao Promotor a prática dos crimes mencionados no Estatuto de Roma, ou se o Conselho de Segurança fizer o comunicado ao Promotor, ou se o próprio Promotor instaurar um inquérito referente a esses crimes, conforme dispõe o artigo 13.

\footnotetext{
${ }^{167}$ BIATO, Marcel Fortuna. O Consenso de Campala. 2010. Disponível em: <http://www.itamaraty.gov.br/salade-imprensa/artigos-relevantes/o-consenso-dekampala-folha-de-s.-paulo-13-8-2010/print-nota $>$. Acesso em 18 de mai. 2015 .
} 
Conforme se infere do artigo 11, item 1, do Estatuto de Roma do Tribunal Penal Internacional trata-se de jurisdição ratione temporis a atribuída para a Corte Internacional Criminal, dispondo que "O Tribunal terá jurisdição unicamente sobre crimes cometidos após a entrada em vigor do presente Estatuto".

Assim, o TPI terá jurisdição sobre crimes cometidos após a entrada em vigor do Estatuto. Entretanto, após a entrada em vigor do Estatuto, se algum Estado resolver se tornar parte posteriormente, o Tribunal Penal Internacional exercerá jurisdição só nos crimes ocorridos após essa manifestação do novo Estado-parte.

Inicialmente destaca-se que a competência é territorial no que se refere a submissão aos Estados que forem signatários do Estatuto de Roma ou por acordo especial, em qualquer Estado, conforme artigo $4^{\circ}$.

A competência é ratione materiae, de acordo com os artigos 5 a 10 do Estatuto de Roma. O TPI tem competência para julgar crimes de genocídio, de guerra e outros crimes contra a humanidade, além de agressão externa. Para esse fim o Rome Statute of the International Criminal Court (Estatuto de Roma da Corte Internacional Criminal) disciplinou os artigos $6^{\circ}$ a $8^{\mathbf{0 1 6 8}}$.

Quanto ao genocídio o artigo II da Convenção de Genocídio de 1945 e, ainda, o artigo $4^{\circ}$ do Estatuto do Tribunal de Ruanda e artigo $2^{\circ}$ do Estatuto do Tribunal da antiga Iugoslávia trouxeram definições que foram encampadas pelo Estatuto de Roma.

Considera-se genocídio (art. $6^{\circ}$ do Estatuto de Roma) a prática, por qualquer pessoa, de uma série de atos, como massacre ou lesão grave de membros de um grupo nacional, étnico, racial ou religioso, com a intenção de destruí-lo, total ou parcialmente.

Já crimes contra humanidade (art. $7^{\circ}$ do Estatuto de Roma) referem-se a escravidão, deportação, extermínio, deslocamento forçado de populações, estupro, prostituição forçada e todo tipo de abuso sexual; bem como perseguição por motivos políticos, raciais ou religiosos, o desaparecimento forçado de pessoas e outros atos desumanos realizados em massa.

Já os crimes de guerra (art. $8^{\circ}$ do Estatuto de Roma) são cometidos no contexto de conflitos armados, sejam nacionais - os mais comuns hoje em dia - ou internacional.

Quanto a perda do direito de punir os crimes supramencionados que estão sob a jurisdição do TPI destaca-se que não prescrevem, conforme dispõe o artigo 29 do Estatuto de Roma.

168 ESTATUTO DE ROMA do Tribunal Penal Internacional. De acordo com o texto aprovado em Roma, no dia 17 de julho de 1998 na Conferência Diplomática de Plenipotenciários das Nações Unidas. 
A disposição sobre a imprescritibilidade não é novidade no cenário internacional, sendo que no caso do Brasil mencionam-se as hipóteses previstas na Constituição Federal de 05/outubro/1988, mencionadas no artigo $5^{\circ}$, sendo que no inciso XLII estabelece-se imprescritível a prática de racismo e no inciso XLIV a ação de grupos armados, civis ou militares, contra a ordem constitucional e o Estado Democrático.

Outrossim, no âmbito brasileiro há propostas para que outras infrações penais sejam imprescritíveis, como por exemplo o caso do homicídio, o que tem sido objeto de debates e pesquisas.

Entende-se que o TPI pode processar qualquer pessoa responsável pela prática de crimes fundamentais com graves violações ao direito internacional humanitário independente do lugar em que foram cometidos, do cargo ou posição que ocupem.

Os países que ratificaram ou aderiram ao Estatuto de Roma se juntaram ao Tribunal e, portanto, são os Estados Partes do TPI que estão sujeitos a Lei Internacional.

The International Criminal Court was established by the Rome Statute of the International Criminal Court, so called because it was adopted in Rome, Italy on 17 July 1998 by the United Nations Diplomatic Conference of Plenipotentiaries on the Establishment of an International Criminal Court.

The Rome Statute is an international treaty, binding only on those States which formally express their consent to be bound by its provisions. These States then become "Parties" to the Statute.

In accordance with its terms, the Statute entered into force on 1 July 2002, once 60 States had become Parties. As of 1 May 2013, 122 States are Parties to the Rome Statute. The States Parties meet in the Assembly of States Parties which is the management oversight and legislative body of the Court. ${ }^{169}$

A partir de 01/maio/2013, 122 Estados Partes passaram a ser signatário do Estatuto de Roma do TPI, todavia, algumas Nações-potências mundiais ainda não aderiram ao TPI, como por exemplo os Estados Unidos.

Após tecer considerações gerais sobre a criação e função do TPI, abordar-se-á o caso específico de Thomas Lubanga, que consistiu na primeira condenação do TPI desde que entrou em funções em 2003.

O caso ganhou grande repercussão internacional considerado o primeiro veredicto da história do TPI, por condenar o ex-chefe rebelde do nordeste congolês ao ter recrutado crianças entre os anos de 2002 e 2003, tornando-as crianças-soldado durante a guerra no leste da República Democrática do Congo (RDC).

169 ICC. International Criminal Court. Establishment of the Court, disponível em <https://www.icccpi.int/en_menus/icc/about \% 20the\% 20court/icc\% 20at\% 20a\%20glance/Pages/establishment\% 20of\% 20th e\% 20court.aspx>. Acesso em 19 de jun. 2015. 


\section{O JULGAMENTO DO CONGOLÊS THOMAS LUBANGA DYILO}

O marco histórico do TPI foi o caso de Thomas Lubanga Dylo, que se trata da primeira condenação após a criação do TPI, após duzentos dias de processo.

O acusado Thomas Lubanga Dylo, nasceu em 29/dezembro/1960 na cidade de Djiba, tornando-se conhecido por ser líder rebelde da República Democrática do Congo. Lubanga aliciava e sequestrava crianças e adolescentes do sexo masculino recrutando-as como soldados e as meninas para servirem de escravas sexuais ${ }^{170}$ dos comandantes, sendo a maioria estuprada entre os anos de 2002 e 2003, durante o período de guerra no Leste da República Democrática do Congo.

Devido a graves violações dos Direitos Humanos, em 23/junho/2004, o Tribunal Penal Internacional abre investigação sobre o caso e em 16 de março de 2006, em Haia Thomas é preso e vai a julgamento. Foi considerado culpado em julho de 2012 por delitos de guerra, recrutamento de menores de 15 anos para força patriótica para libertação do Congo a mais de 14 anos de prisão, por ter provocado a morte de mais de sessenta mil pessoas, desde 1999 . Segundo a Organização das Nações Unidas:

Na audiência pública do TPI, o Juiz Presidente da Câmara de Julgamento, Adrian
Fulford, explicou que a Câmara considerou a gravidade dos crimes, a extensão do
dano causado, e em particular "os danos causados às vítimas e suas famílias, a
natureza do comportamento ilegal e os meios utilizados para executar o crime; o nível
de participação da pessoa condenada; o grau de intenção; as circunstâncias, local,
idade e as condições econômicas e sociais do condenado". O Juiz Fulford também
destacou que os crimes pelos quais Lubanga foi condenado foram crimes graves que
afetam a comunidade internacional como um todo, observando que a vulnerabilidade
"das crianças significa que eles precisam ser objeto de proteção especial, que não se
aplica à população em geral, conforme reconhecido em vários tratados internacionais.
171

A condenação de Thomas Lubanga em crimes graves contra humanidade deu-se sobretudo em razão da vulnerabilidade das crianças e adolescentes, posto serem objeto de proteção especial, tanto na legislação de cada país, como é o caso no Código Penal Brasileiro, Estatuto da Criança e Adolescente quanto em Tratados Internacionais. Várias ONGS

\footnotetext{
${ }^{170}$ REVISTA ÉPOCA. Lubanga é condenado por transformar crianças em soldados. Edição de 14 de mar. 2012.

${ }^{171}$ ONU Brasil. TPI sentencia ex-senhor da guerra congolês. Disponível em: <http://www.onu.org.br/tribunalpenal-internacional-sentencia-ex-senhor-da-guerra-congoles-a-14-anos-de-prisao/ > Acesso em 02 fev. 2014.
} 
Internacionais de defesa dos Direitos Humanos acompanharam o julgamento, dentre ela a ONG de defesa dos direitos humanos Human Rights Watch (HRW) seguiu o processo e a representante Geraldine Matioli-Zeltner manifestou que:

a sentença seja um aviso para todos aqueles que recrutam crianças soldados para as guerras dos adultos. Esperamos que outros ouçam este aviso, em particular Bosco Ntaganda, que comanda uma nova rebelião no leste do Congo democrático. Ele tem cometido naquela região o mesmo crime que Lubanga cometeu ${ }^{172}$.

O acusado permaneceu preso de 2006 até o julgamento em 2009, tendo ocorrido a detração de sua pena.

\subsection{Sequência cronológica do procedimento}

Em 21 de junho de 2004 a Corte Penal Internacional inicia sua primeira investigação penal referente a crime de guerra em relação a Thomas Lubanga Dylo, haja vista suas práticas criminosas entre 2002 e 2003 na República Democrática do Congo, ocasião em que morreram cerca de 60.000 pessoas e outras milhares ficaram desaparecidas.

Os autos em trâmite no Tribunal Penal Internacional (TPI) seguiram o trâmite previsto no Estatuto, conforme ordem cronológica a seguir.

17 março 2006: Lubanga é o primeiro suspeito a ser detido e transferido para o TPI. A apreensão de thomas Lubanga Dylo foi realizada por Amy K. Rolfvondenbaumen. 20 março 2006: Lubanga é acusado.

29 janeiro 2007: Juízo de Instrução confirma as acusações contra Lubanga para o crime de guerra de recrutar ou alistar crianças-soldados ou utilizá-los para participar ativamente nas hostilidades.

No TPI o procedimento de julgamento basicamente ocorre em duas fases: $1^{a}$ fase na Câmara de Juízo de Instrução e a $2^{\mathrm{a}}$ fase na Câmara de Julgamento.

Os eventos mencionados acima referem-se a Fase na Câmara de Juízo de Instrução, na qual medidas investigatórias e a proteção de vítimas ou de interesses gerais da defesa são submetidos à autorização ou supervisão da Câmara.

$\mathrm{Na} 2^{\mathrm{a}}$ fase a Câmara do Julgamento se pronuncia sobre a procedência da acusação. No caso abordado neste estudo Thomas Lubanga foi acusado de crimes de guerra e contra humanidade (artigo $6^{\circ}$ genocídio e artigo $7^{\circ}$ crimes contra humanidade). Na sequência os fatos em destaque foram:

172 DEUTSCHE WELLE DW. Thomas Lubanga é condenado. Disponível em:<http://www.dw.de/thomaslubanga> Acesso em 29 de jan. 2014. 
13 junho 2008: Na Câmara de Julgamento aponta-se falha da acusação de divulgar documentos de defesa e ordena a liberação de Lubanga pendente de recurso por parte do Gabinete do Procurador (OTP).

21 outubro 2008: A Câmara de Apelações, em duas decisões, confirma a falha, mas reforma a decisão sobre a liberação de Lubanga.

18 novembro 2008: A Câmara de Julgamento saneia questões pendentes e autoriza que a Defesa de Lubanga tenha acesso a todos os elementos probatórios juntados aos autos. Além disso, designa o 26 janeiro de 2009 como data do julgamento provisório. 26 janeiro 2009: A Câmara de Julgamento declarada aberto o julgamento de Lubanga. Na ocasião Lubanga afirma não ser culpado das três acusações de crimes de guerra, de alistar e recrutar crianças-soldados.

14 julho 2009: Procuradoria conclui a acusação de seu caso contra Lubanga.

Até esse momento foram 74 (setenta e quatro) dias de audiências com a oitiva de 28 testemunhas. Nesse momento processual seria a vez da Defesa apresentar suas alegações, contudo, a Câmara do Julgamento adia o julgamento em razão da existência de recurso referente qualificação jurídica dos fatos e possíveis condenações por outros crimes, com base nas provas apresentadas.

Neste aspecto frisa-se que o Estatuto de Roma do TPI dispõe no artigo 22 sobre o princípio do nullum crimen sine lege e no artigo 23 sobre o princípio da nulla poena sine lege.

$\mathrm{O}$ artigo 22, item 2, do Estatuto de Roma dispõe que "a definição de um crime será interpretada de modo restrito, e não de forma extensiva por analogia", sendo ainda, que em "caso de ambiguidade, a definição será interpretada em favor da pessoa investigada, processada ou condenada".

2 outubro 2009: A Câmara de Julgamento adia o início da alegação da Defesa até que a Câmara de Apelações decida sobre um recurso relacionado com a qualificação jurídica dos fatos do caso, especificamente se Lubanga poderia ser condenado por outros crimes, com base nas provas apresentadas.

08 dezembro 2009: A Câmara de Apelações profere decisão do juízo de julgamento sobre a possível adição de acusações.

Após essa interrupção e questão processual dirimida, o julgamento da questão principal é retomado, porém novos adiamentos ocorrerão conforme se observa a seguir até a prolação da sentença condenatória.

Nesses adiamentos e questões suscitadas, a Câmara de Julgamento evidentemente procurou equilibrar os interesses das partes, em que pese na busca pelo devido processo legal tenha por vezes feito isso em detrimento da segurança de testemunhas e vítimas e, ainda, de pessoa intermediária que trabalhou na coleta das provas.

07 janeiro 2010: O julgamento recomeça com a apresentação da alegação da defesa. 
08 julho 2010: os juízes suspendem o processo devido à recusa do Procurador em cumprir uma ordem para revelar a identidade de um intermediário usado para reunir provas.

08 outubro 2010: A Câmara de Apelações analisa outras questões processuais quanto a aplicação de sanções e/ou outras medidas menos drásticas disponíveis.

20 maio 2011: Os Juízes decidem mais questões processuais.

25 e 26 agosto 2011: A Câmara de Julgamento retomada o procedimento e ouve declarações finais e deliberações.

Nos termos do artigo 66 do Estatuto de Roma, assim como também ocorre em diversos países, dentre eles o Brasil, Thomas Lubanga goza da presunção de inocência, que vigora até que o seja provada a sua culpa no Tribunal, sendo o Promotor é quem tem o ônus de provar a culpabilidade do acusado.

14 março 2012: Os Juízes declaram Lubanga culpado de recrutar crianças-soldados com idade inferior a 15 anos. O veredicto está sujeito a recurso.

07 agosto 2012: Os Juízes no caso Lubanga TPI tratam sobre as reparações para as vítimas, estabelecendo princípios a serem aplicados, sendo que a reparação será implementadas pelo TPI através do Fundo Fiduciário para as Vítimas. Também é concedida uma espécie de licença à defesa para recorrer da decisão quanto às reparações.

A sentença condenatória foi proferida em francês, língua que o acusado compreendia e falava fluentemente, determinando 14 anos de prisão para Lubanga.

Conforme artigo 77 do Estatuto era possível pena de reclusão de até 30 anos, o que foi postulado pelo Promotor, porém a acusação como pedido alternativo sugeriu pena de 20 anos, caso Lubanga apresentasse pedido de desculpas em audiência pública e se comprometesse em trabalhar em probl da paz em Ituri/Congo.

Conforme a American Non-Governmental Organizations Coalition for the International Criminal Court (AMICC), após a intimação da sentença, o acusado teve 30 (trinta) dias para apresentar eventual recurso, sendo que a Defesa recorreu do julgamento da Câmara de Julgamento e o Ministério Público também o fez em outubro de 2012.173

A condenação proferida pelo pelo TPI no Caso Thomas Lubanga teve grande repercussão no cenário internacional principalmente por envolver jovens, crianças raptadas para servir em exército de milícias, expondo graves violações aos Direitos Humanos.

Dentre as várias manifestações em âmbito internacional cita-se o Fundo das Nações Unidas para Criança - UNICEF celebrando a condenação histórica, vez que a primeira do TPI e envolvendo interesse de crianças e adolescentes:

173 AMICC. American Non-Governmental Organizations Coalition for the International Criminal Court Case: Prosecutor x Thomas Lubang. Disponível em: <http://www.amicc.org/icc/lubanga> Acesso em 28/01/2014. 
Esta é uma vitória essencial para a proteção das crianças em conflitos", disse Anthony Lake, diretor-executivo do Unicef. "A condenação de Thomas Lubanga pelo TPI manda uma clara mensagem a todos os grupos armados que escravizam e brutalizam crianças: a impunidade não será tolerada ${ }^{174}$.

No mesmo sentido a Agência Angola Press também registrou o edito condenatório, bem como destacando sua importância por vários motivos, dentre eles os direitos humanos violados no Congo no que se refere a crianças e adolescentes, conforme leitura do resumo da sentença pelo juiz britânico Adrian Fulford:

O Tribunal concluiu por unanimidade que a acusação demonstrou, além de qualquer dúvida razoável, que Thomas Lubanga é culpado de crimes de recrutamento de crianças de menos de 15 anos e de tê-los obrigado a participar num conflito armado. 175

Muitas foram as agências, organismos e instituições internacionais e Estados que se posicionaram política, jurídica e socialmente sobre a decisão do TPI, o que encontra eco na tese de Ulrich Beck ${ }^{176}$ quando discorre sobre a nova cultura política mencionando os direitos fundamentais:

Efeito amplificador: os direitos fundamentais podem ser fruídos sucessivamente e construídos de modo a reforçarem-se mutuamente, fortalecendo assim o 'poder de resistência' das 'bases' e das 'instâncias subalternas' em face de intervenções indesejadas 'de cima'. A crescente autoconfiança e o interesse participativo dos cidadãos, sobre o que as pesquisas de opinião fazem saber de uma forma impressionante, assim como a pluralidade de iniciativas variadas de cidadãos e movimentos políticos [...]

A condenação do chefe de milícias congolesas Thomas Lubanga foi a primeira do TPI e assim inaugura uma fase de fim da cultura de impunidade de pessoas que são violadoras em massa dos direitos humanos. Isso provoca inevitavelmente a manifestação dos mais variados movimentos e da comunidade contemporânea globalizada, desenvolvendo gradativamente sua capacidade de ser global e local, isto é, um cidadão 'glocal', que age localmente, mas pensa globalmente, conforme defendido por Guimarães ${ }^{177}$ e criticado por Falcão ${ }^{178}$. É o embrião de

\footnotetext{
${ }^{174}$ REVISTA ÉPOCA. Lubanga é condenado por transformar crianças em soldados. Edição de 14 de mar. 2012

${ }^{175}$ ANGOP. AGÊNCIA ANGOLA PRESS. Antigo chefe de milícia congolesa Thomas Lubanga condenado. Disponível em: <http://www.portalangop.co.ao/angola/pt_pt/noticias/africa/2012/2/11/Antigo-chefe-miliciacongolesa-Thomas-Lubanga-condenado>. Acesso em 02 de fev. 2014.

${ }^{176}$ BECK, Ulrich. Sociedade de Risco: rumo a outra modernidade. $1^{a}$ reimpressão da $2^{a}$ edição. São Paulo: Editora 34, 2013. p.290.

177 GUIMARÃES, Mauro. A formação de educadores ambientais. $3^{\mathrm{a}}$ edição. Campinas: Papirus Editora, 2007. p.77.

${ }^{178}$ FALCÃO, Joaquim. Pense localmente e aja globalmente. Democracia, direito e terceiro setor. $2^{\mathrm{a}}$ edição. Rio de Janeiro: FGV Editora, 2006. p.73-76
} 
uma cidadania planetária que pode ser ou não favorável para o futuro dos direitos humanos. A posteridade dirá.

\section{CONSIDERAÇÕES FINAIS}

O presente artigo abordou o Tribunal Penal Internacional (TPI) destacando sua criação, jurisdição e competência, correlacionando com o julgamento do congolês Thomas Lubanga em razão de violação em massa dos direitos humanos.

Desde a criação do Tribunal Penal Internacional (TPI) em 2002, através do Estatuto de Roma, mais de duas dezenas de pessoas foram indiciados, sendo que mais de uma dezena encontra-se na condição processual de foragido e grande parte desses últimos exercem altos cargos em seus países.

Destacou-se que o TPI exerce sua jurisdição sobre pessoas e não sobre Estados em razão da prática de crimes graves de transcendência internacional.

A primeira condenação do TPI desde que a Corte Internacional iniciou seus trabalhos, destaca-se como marco histórico, vez que sentenciou a 14 anos de prisão Thomas Lubanga com então 51 anos é considerando-o culpado por crimes de guerra, por ter utilizado como soldado crianças com menos de 15 anos de idade, obrigado-as a matar, usar drogas e por abuso sexual praticados contra elas.

A trajetória de discussão política e jurídica foi longa, defendendo-se a aplicação do princípio da justiça universal e criação de um Tribunal que fosse permanente para julgamento de crimes de guerra.

A criação e atuação do TPI, mormente com a sentença condenatória do caso aqui abordado sinaliza no sentido de uma caminhada rumo ao fim de uma cultura de impunidade diante de práticas criminosas de violação em massa dos direitos humanos.

Os primeiros passos foram dados e a esperança da população mundial é poder dizer no futuro que assim continuou caminhando a humanidade.

\section{REFERÊNCIAS}

ALVES JUNIOR, Oscar Francisco. Estatuto da Criança e do Adolescente: O Conselho Tutelar e sua Prática Educativa. Revista Emeron nº 23, 2012. 
AMICC. American Non-Governmental Organizations Coalition for the International Criminal Court Case: Prosecutor $x$ Thomas Lubang. Disponível em: $<$ http://www.amicc.org/icc/lubanga> Acesso em 28/01/2014.

ANGOP. AGÊNCIA ANGOLA PRESS. Antigo chefe de milícia congolesa Thomas Lubanga condenado. Disponível em: <http://www.portalangop.co.ao/angola/pt_pt/noticias/africa/2012/2/11/Antigo-chefe-miliciacongolesa-Thomas-Lubanga-condenado>. Acesso em 02 de fev. 2014.

BECK, Ulrich. Sociedade de Risco: rumo a outra modernidade. $1^{\text {a }}$ reimpressão da $2^{\text {a }}$ edição. São Paulo: Editora 34, 2013.

BIATO, Marcel Fortuna. O Consenso de Campala. 2010. Disponível em: $<$ http://www.itamaraty.gov.br/sala-de-imprensa/artigos-relevantes/o-consenso-dekampalafolha-de-s.-paulo-13-8-2010/print-nota>. Acesso em 18 de mai. 2015.

BOBBIO, Norberto. A era dos Direitos. 15ª tiragem. Rio de Janeiro: Campus, 1992.

CAPRA, Fritjof. O ponto de mutação. 30ª reimpressão. São Paulo: Cultrix, 2014.

COMPARATO, Fábio Konder. A Afirmação Histórica dos Direitos Humanos. $7^{a}$ ed. São Paulo: Saraiva, 2010.

DEUTSCHE WELLE DW. Thomas Lubanga é condenado. Disponível em: <http://www.dw.de/thomas-lubanga $>$ Acesso em 29 de jan. 2014.

ESTATUTO DE ROMA do Tribunal Penal Internacional. De acordo com o texto aprovado em Roma, no dia 17 de julho de 1998 na Conferência Diplomática de Plenipotenciários das Nações Unidas

FALCÃO, Joaquim. Pense localmente e aja globalmente. Democracia, direito e terceiro setor. $2^{\mathrm{a}}$ edição. Rio de Janeiro: FGV Editora, 2006.

GARCIA, Marcos Leite. Direitos Humanos como conceito histórico da humanidade. IV Encontro Anual da Andhep. Vitória, 2008. p.8, disponível em $<$ http://www.andhep.org.br/anais/arquivos/IVencontro/MarcosLeiteGarcia.pdf >. Acesso em 15 de jul. 2015. 
GUIMARÃES, Mauro. A formação de educadores ambientais. $3^{\mathrm{a}}$ edição. Campinas: Papirus Editora, 2007.

ICC. International Criminal Court. Establishment of the Court, disponível em $<$ https://www.icc-

cpi.int/en_menus/icc/about\%20the \%20court/icc\%20at\%20a\%20glance/Pages/establishment\% 20of\%20the\%20court.aspx>. Acesso em 19 de jun. 2015.

LEWANDOWSKI, Enrique Ricardo. O Tribunal Penal Internacional: de uma cultura de impunidade para uma cultura de responsabilidade, disponível em <http://www.scielo.br/scielo.php?script=sci_arttext\&pid=S0103-40142002000200012\#not1>. Acesso em: 20 de ago. 2015.

ONU Brasil. TPI sentencia ex-senhor da guerra congolês. Disponível em: $<$ http://www.onu.org.br/tribunal-penal-internacional-sentencia-ex-senhor-da-guerra-congolesa-14-anos-de-prisao/ > Acesso em 02 fev. 2014.

PASSOLD, Cesar Luiz. Metodologia da Pesquisa Jurídica: teoria e prática. $12^{\mathrm{a}}$ ed. São Paulo: Conceito Editorial, 2011.

PECES-BARBA, Gregorio. La diacronía del fundamento y del concepto de los Derechos: el tiempo de la historia. Curso de Derechos Fundamentales: teoría general. Madrid: Universidad Carlos III de Madrid, 1995, cap V.

PIOVESAN, Flávia. Direitos Humanos e o Direito Constitucional Internacional. 3. ${ }^{a}$ ed. Max Lemonad, 1997.

REVISTA ÉPOCA. Lubanga é condenado por transformar crianças em soldados. Edição de 14 de mar. 2012. 
This article discusses the creation of the International Criminal Court (ICC), its importance in the international arena, from its adopted position against mass violation of Human Rights, which ordered the arrest and after due process of law the subsequent conviction of Thomas Lubanga Dyilo, former Congolese rebel leader from northeast to have recruited children and adolescents making them soldiers and sexual slaves girls during the war in the eastern Democratic Republic of Congo. The exposed-historical literature argumentative form identifies the ICC as one of the instruments for global governance in the third millennium, with regard to the prosecution and trial in criminal cases.

Keywords: Human rights. International criminal court. Children. Condemnation. 